\title{
ANALISIS HAMBUR BALIK AKUSTIK UNTUK KLASIFIKASI DAN PEMETAAN SUBSTRAT DASAR PERAIRAN DI TELUK YOS SUDARSO, KOTA JAYAPURA
}

\section{ACOUSTICS BACKSCATTERING ANALYSIS TO CLASSIFICATION AND MAPPING OF SEABED SUBSTRATE IN YOS SUDARSO BAY, JAYAPURA CITY}

\author{
Baigo Hamuna $^{1 *}$, Sri Pujiyati ${ }^{2}$, Nyoman Metta N. Natih ${ }^{2}$, dan Lisiard Dimara ${ }^{1}$ \\ ${ }^{1}$ Jurusan Ilmu Kelautan dan Perikanan, FMIPA - Universitas Cenderawasih, Jayapura \\ ${ }^{2}$ Departemen Ilmu dan Teknologi Kelautan, FPIK - Institut Pertanian Bogor, Bogor \\ *E-mail: bhamuna@yahoo.com.sg
}

\begin{abstract}
The objective of this study was to analyze the characteristics of seabed acoustics backscattering strength. The Simrad EK15 single beam echosounder, with frequency $200 \mathrm{kHz}$ used for recordings of hydroacoustics data on 29 April to 2 May 2017 in the Yos Sudarso Bay, Jayapura City, Papua Province. Substrate sample used for data validation using sediment grab. The data processing of acoustics data using elementary sampling distance unit is 100 ping and threshold $-50 \mathrm{~dB}$ for E1 value and threshold $-70 \mathrm{~dB}$ for E2 value. The results of study shown the significant difference of acoustics backscattering of seabed substrate type. The E1 value of coral are $-15.62 \mathrm{~dB}$ and E2 value are $-30.70 \mathrm{~dB}, E 1$ value of sand are varied between $-28.40 d B$ up to $-27.36 d B$ and $E 2$ value varied between $-50.96 d B$ up to $-47.44 d B$, $E 1$ value of mud are varied between $-37.81 \mathrm{~dB}$ up to $-35.99 \mathrm{~dB}$ and E2 value varied between $62.85 \mathrm{~dB}$ up to $-54.12 \mathrm{~dB}$. Substrate grain size has an effect on seabed acoustics backscattering strength. Based on result of acoustics detection, corals is at a depth of 2-3 m, sand at a depth of 2-10 $\mathrm{m}$ and mud is dominant at a depth of more than $10 \mathrm{~m}$.
\end{abstract}

Keywords: acoustics backscattering, E1, E2, seabed substrate, Yos Sudarso Bay

\begin{abstract}
ABSTRAK
Penelitian ini bertujuan untuk mengkaji karakteristik kuat hambur balik akustik dasar perairan. Echosounder bim tunggal Simrad EK15 frekuensi $200 \mathrm{kHz}$ digunakan untuk perekaman data hidroakustik yang dilaksanakan pada tanggal 29 April sampai 2 Mei 2017 di perairan Teluk Yos Sudarso, Kota Jayapura, Provinsi Papua. Pengambilan contoh substrat digunakan untuk data validasi menggunakan sedimen grab. Pengolahan data hasil rekaman akustik menggunakan satuan dasar pencuplikan sebesar 100 ping data perekaman dengan ambang batas nilai E1 adalah $-50 \mathrm{~dB}$ dan E2 adalah $-70 \mathrm{~dB}$. Hasil penelitian menunjukkan bahwa terdapat perbedaan yang signifikan nilai hambur balik akustik antar tipe substrat dasar perairan. Nilai E1 karang -15,62 dB dan E2 -30,70 dB, untuk substrat pasir E1 berkisar antara $-28,40 \mathrm{~dB}$ sampai $-27,36 \mathrm{~dB}$ dan E2 berkisar antara $-50,96 \mathrm{~dB}$ sampai $-47,44 \mathrm{~dB}$, sedangkan substrat lumpur E1 berkisar antara $-37,81 \mathrm{~dB}$ sampai $-35,99 \mathrm{~dB}$ dan E2 berkisar antara $-62,85 \mathrm{~dB}$ sampai $-54,12 \mathrm{~dB}$. Ukuran butiran substrat sangat berpengaruh terhadap kuat hambur balik akustik dasar perairan. Berdasarkan hasil deteksi akustik, substrat karang berada pada kedalaman 2-3 m, substrat pasir kedalaman 2-10 m, dan substrat lumpur dominan kedalaman lebih dari $10 \mathrm{~m}$.
\end{abstract}

Kata kunci: hambur balik akustik, E1, E2, substrat dasar perairan, Teluk Yos Sudarso

\section{PENDAHULUAN}

Substrat dasar perairan memegang peranan penting sebagai habitat bagi berbagai macam biota mikrofauna maupun makrofauna dasar perairan, termasuk sebagai bagian dari habitat ikan yang menghuni perairan dekat dasar. Berbagai metode telah 
dikembangkan dalam upaya mengkaji karakteristik, klasifikasi dan penyebaran substrat dasar perairan, salah satunya metode hidroakustik yang memanfaatkan gelombang suara untuk mendeteksi objek dalam perairan. Dewasa ini, teknologi hidroakustik telah banyak digunakan untuk memetakan dan mengklasifikasikan dasar perairan dan kandungan sumberdaya hewan bentik yang ada di dasar perairan, tipe substrat dan biota bentik. Perkembangan dalam mengklasifikasikan substrat dasar perairan menjadikan hidroakustik sebagai alat yang efektif untuk memantau dan pemetaan parameter habitat dasar perairan. Selain itu, dengan menggunakan teknologi hidroakustik dapat membedakan dan mengelompokkan berbagai tipe substrat dasar perairan.

Dasar perairan memiliki karakteristik dalam memantulkan dan menghamburkan kembali gelombang suara. Efek pantulan dan backscattering yang dihasilkan dasar perairan lebih kompleks karena sifat dasar laut yang tersusun dari berbagai unsur mulai dari lapisan bebatuan yang kasar hingga lempung dan tersusun atas lapisan-lapisan yang memiliki komposisi yang berbeda (Urick, 1983). Pemanfaatan teknologi hidroakustik dalam memetakan dan mengklasifikasikan dasar perairan didasari bahwa parameter fisik dasar perairan yang sangat bervariasi, seperti tingkat kekasaran dan kekerasan dasar perairan, ukuran butiran sedimen dan relief dasar perairan. Kondisi fisik dasar perairan yang bervariasi akan mempengaruhi pantulan sinyal akustik, seperti tingkat karakterisitk dasar perairan, ukuran butiran sedimen dan relief dasar dapat mempengaruhi proses hamburan balik sinyal akustik (Thermo et al., 1988; Demer et al., 2009; Pujiyati et al., 2010). Perbedaan karakterisitik tipe dasar perairan dapat digambarkan melalui tingkat kekasaran (roughness) dan kekerasan (hardness) dasar perairan seperti batu, pasir, lumpur atau campurannya (Penrose et al., 2005).

Echosounder single beam merupakan instrumen akustik yang paling sederhana yang hanya memiliki satu bim untuk mendeteksi target masuk dalam cakupan pancarannya. Beberapa kelebihan penggunaan echosounder single beam untuk survei substrat dasar perairan yang meliputi efisiensi dan prosedur pengolahan data yang standar, pengoperasian alat yang relatif mudah serta tingkat akurasi tinggi baik dalam resolusi maupun presisi hasil (Anderson et al., 2008). Klasifikasi dasar perairan menggunakan metode akustik single beam telah mengungkapkan kemampuannya untuk membedakan berbagai jenis dasar perairan dan mengelompokkannya berdasarkan sifat pantulan akustik yang berbeda (Freitas et al., 2008). Berbagai penelitian telah dilakukan untuk mengklasifikasikan dan memetakan substrat dasar perairan menggunakan metode akustik single beam dengan penggunaan berbagai tipe instrumen yang berbeda. Manik (2015) membedakan pantulan akustik dasar perairan pasir, lumpur dan lempung menggunakan echosounder single beam Cruzpro dengan frekuensi 50, 120 dan 200 $\mathrm{kHz}$, Gleason et al. (2008) memetakan dasar perairan dengan menggunakan QTC System dan Demer et al. (2009) dapat membedakan antara echo ikan, zooplankton dan dasar perairan dengan menggunakan echosounder multi frekuensi.

Hasil penelitian ini diharapkan dapat digunakan sebagai bahan masukan untuk memetakan profil substrat dasar di perairan Teluk Yos Sudarso, Kota Jayapura. Penelitian ini dilakukan untuk mengkaji karakteristik nilai hambur balik akustik dasar perairan menggunakan echosounder single beam, sehingga memudahkan dalam melakukan pemetaan dasar perairan tanpa harus melakukan pengambilan sampel dasar perairan.

\section{METODE PENELITIAN}

\subsection{Waktu dan Tempat Penelitian}

Penelitian ini dilaksanakan pada tanggal 29 April - 2 Mei 2017 dengan lokasi penelitian di perairan Teluk Yos Sudarso, Kota Jayapura Provinsi Papua (Gambar 1). 


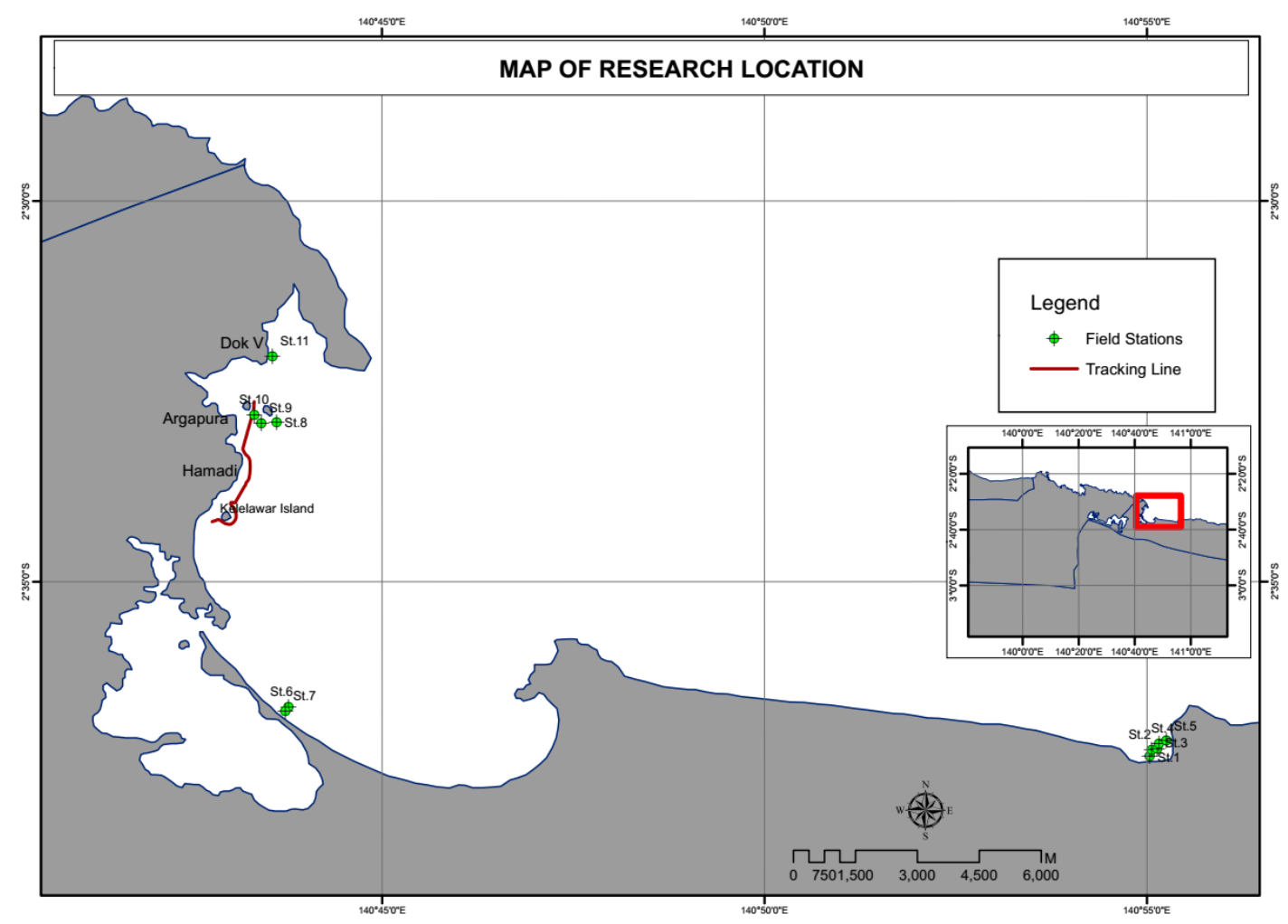

Gambar 1. Peta lokasi penelitian.

\subsection{Pengambilan Data}

Peralatan yang digunakan pada penelitian ini meliputi instrumen echosounder single beam SIMRAD EK15 (spesifikasi pada Tabel 1), laptop, GPS, kapal nelayan, sedimen grab, kantung plastik dan shieve shaker. Perangkat lunak yang digunakan untuk pemrosesan data meliputi perangkat lunak Echoview 4.0, SPSS, Microsoft Excel dan ArcGIS 10.5.

\section{Tabel 1. Spesifikasi SIMRAD EK15} (Simrad, 2012).

\begin{tabular}{lc}
\hline \multicolumn{1}{c}{ Parameter } & Keterangan \\
\hline Tipe transduser & Single beam \\
Frekuensi & $200 \mathrm{kHz}$ \\
Ping rate & $>40 \mathrm{~Hz}$ \\
Durasi pulsa & $80-1240 \mu \mathrm{s}$ \\
Panjang pulsa & $0,16 \mathrm{~ms}$ \\
Lebar beam & $26^{\circ}$ \\
Output power & $45 \mathrm{~W}$ \\
\hline
\end{tabular}

Pengambilan data akustik dilakukan menggunakan instrumen hidroakustik sistem single beam SIMRAD EK15. Perekaman data akustik dilakukan secara stasioner dan tracking. Perekaman secara stasioner dilakukan pada kondisi kapal dalam keadaan diam pada 11 stasiun dengan tipe subsrat yang berbeda dengan waktu perekaman selama 5 sampai 10 menit. Perekaman tracking data akustik dilakukan pada lintasan yang telah ditentukan tanpa mengetahui tipe substrat dasar perairan sebelumnya dengan kecepatan kapal maksimal 4 knot. Kedua jenis data akustik tersebut (stasioner dan tracking) akan dianalisis secara statistik untuk mengetahui pengelompokkan nilai pantulan akustik dan dapat digunakan untuk menentukan tipe substrat dasar perairan pada perekaman tracking. Selain perekaman data akustik, dilakukan pengukuran parameter oseanografi seperti suhu, salinitas dan $\mathrm{pH}$ yang akan digunakan sebagai kalibrasi hasil perekaman akustik. 
Pengambilan contoh substrat dasar perairan hanya dilakukan secara stasioner pada stasiun 1 sampai stasiun 10 , adapun pada stasiun 11 tidak dilakukan pengambilan contoh substrat karena substrat dasar perairan berupa karang. Pengambilan contoh substrat dilakukan tepat berada di bawah transducer menggunakan sedimen grab $(20 \times 20 \mathrm{~cm})$ setelah perekaman akustik. Klasifikasi tekstur substrat dasar perairan dilakukan di laboratorium dengan menggunakan metode ayakan bertingkat (shieve shaker), sedangkan klasifikasi campuran substrat dasar perairan dilakukan berdasarkan komposisi partikel di dalam substrat tersebut dengan menggunakan diagram segitiga sedimen (Krumbien and Sloss, 1951).

\subsection{Pemrosesan dan Analisis Data}

Nilai volume backscattering (SV) dasar perairan diekstrak menggunakan perangkat lunak Echoview 4.0. Data pantulan akustik dasar perairan yang diperoleh terdiri dari data pantulan pertama (E1) dan pantulan kedua (E2) dari hasil perekaman secara stasioner dan tracking. Proses membedakan echo pantulan akustik dilakukan dengan mengkuantifikasi sinyal echo yang diperoleh untuk menghasilkan suatu data berdasarkan nilai rata-rata pantulan akustik dasar perairan. Penggunaan threshold (nilai ambang batas) dalam pengolahan nilai SV (E1 dan E2) mengacu pada Pujiyati et al. (2010), dimana nilai E1 diolah menggunakan threshold minimal $-50.00 \mathrm{~dB}$ dan maksimum $0 \mathrm{~dB}$, sedangkan nilai E2 diolah menggunakan threshold minimal $-70.00 \mathrm{~dB}$ dan maksimum 0 dB. Satuan dasar pencuplikan (Elementary Sampling Distance Unit, ESDU) yang digunakan pada proses pengolahan data untuk mengetahui nilai pantulan akustik dasar perairan adalah 100 ping. Adapun ketebalan integrasi nilai E1 dan E2 adalah sebesar $0.2 \mathrm{~m}$ yang disesuaikan dengan ketebalan sedimen grab yang digunakan pada pengambilan sampel substrat dasar perairan.
Analisis statistika yang digunakan dalam penelitian ini adalah analisis regresi dan analisis multivarian. Analisis regresi digunakan untuk mengetahui hubungan persentase ukuran butiran substrat berupa pasir kasar, pasir halus dan lumpur terhadap nilai kuat hambur balik akustik dasar perairan (E1) yang diperoleh pada perekaman stasioner. Analisis multivarian digunakan untuk klasifikasi dan pengelompokan nilai hambur balik dasar perairan. Metode yang digunakan untuk analisis multivarian adalah analisis clustering, yaitu analisis multidimensional yang terdiri dari pembagian parameterparameter (deskriptor) dalam suatu penelitian (Legendre dan Legendre, 1998). Data yang digunakan dalam analisis clustering adalah nilai E1 dan E2 dari data hasil perekaman stasioner dan tracking. Tujuan dari analisis tersebut adalah untuk menentukan kelas kategori dengan pendekatan hirarki untuk menentukan tingkat kemiripan nilai E1 dan E2 yang diperoleh dari hasil perekaman secara stasioner dan tracking. Tingkat kemiripan ditentukan menggunakan metode Euclidean Distance, dimana data yang mirip akan ditempatkan pada hirarki yang berdekatan dan yang tidak mirip pada hirarki yang berjauhan.

\section{HASIL DAN PEMBAHASAN}

\subsection{Hambur Balik Akustik Dasar Perairan}

Sinyal akustik yang dipantulkan dari dasar perairan ditentukan oleh jenis substrat dasar perairan. Dasar perairan memiliki karakteristik yang kompleks sehingga intensitas sinyal akustik yang dipantulkan akan berbeda antara substrat yang satu dengan lainnya. Hambur balik akustik dasar perairan dapat dikuantifikasi dalam bentuk volume backscattering strength (SV). SV merupakan perbandingan antara kekuatan intensitas suara yang dipantulkan dengan intensitas suara yang mengenai dasar perairan yang terintegrasi pada volume 
tertentu (ketebalan dasar perairan). Tabel 2 menyajikan hasil kuantifikasi nilai SV substrat dasar perairan berupa karang, pasir dan lumpur yang diperoleh dari hasil perekaman secara stasioner.

Nilai SV hasil rekaman akustik terdiri atas pantulan pertama (E1) dan pantulan kedua (E2). E1 merupakan gema yang berasal dari dasar perairan yang langsung diterima transduser yang menunjukkan tingkat kekasaran dasar perairan, sedangkan E2 yamg menunjukkan tingkat kekerasan dasar perairan merupakan gema yang berasal dari dasar perairan kemudian kembali ke transduser tetapi dipantulkan oleh permukaan perairan dan kembali ke dasar perairan dan kemudian dipantulkan kembali lagi ke transduser (Penrose et al., 2005). Chivers et al. (1990) menyataan bahwa nilai E2 yang tinggi berasal dari substrat yang keras dan nilai E2 yang rendah berasal dari substrat yang lunak. Perbedaan nilai E1 dan E2 disebabkan oleh beberapa faktor, antara lain berkurangnya energi pantulan karena pengaruh jarak, penyerapan energi oleh medium air laut serta penyebaran energi pada medium air laut tersebut.
Berdasarkan Tabel 2 bahwa terdapat perbedaan antara intensitas nilai SV berupa nilai E1 dan E2 yang dihasilkan oleh substrat dasar perairan karang, pasir dan lumpur. Hambur balik akustik dari karang memiliki nilai paling besar dibandingkan hambur balik akustik dari pasir maupun lumpur. Menurut Satyamarayana et al. (2007) dan Siwabessy et al. (2006) bahwa nilai kekerasan maupun kekasaran dasar perairan secara akustik akan meningkat pada substrat lumpur menuju batuan. Selain itu, tingginya tingkat penetrasi dan pantulan (refleksi) dasar perairan sangat dipengaruhi oleh jenis substrat dasar perairan tersebut.

Keras atau lunaknya dasar perairan akan memberikan pengaruh terhadap intensitas pantulan yang dikembalikan, dimana dasar perairan yang keras memiliki pantulan yang lebih besar dari dasar perairan yang halus (Siwabessy, 2001; Hamilton, 2001). Subsrat dasar perairan yang keras seperti batu atau karang akan menghasilkan intensitas pantulan E1 maupun E2 yang tinggi, sebaliknya dasar perairan yang lunak seperti pasir, lumpur dan lempung akan menghasilkan pantulan yang lemah (Gambar 2).

Tabel 2. Nilai hambur balik akustik dasar perairan hasil perekaman stasioner.

\begin{tabular}{|c|c|c|c|c|c|c|c|}
\hline \multirow[b]{2}{*}{ St. } & \multirow[b]{2}{*}{$\begin{array}{c}\text { Kedalaman } \\
\text { (m) }\end{array}$} & \multicolumn{2}{|c|}{ SV } & \multicolumn{3}{|c|}{ Fraksi Substrat (\%) } & \multirow[b]{2}{*}{ Tipe Substrat } \\
\hline & & $\begin{array}{c}\mathrm{E} 1 \\
(\mathrm{~dB})\end{array}$ & $\begin{array}{c}\mathrm{E} 2 \\
(\mathrm{~dB})\end{array}$ & $\begin{array}{c}\text { Pasir } \\
(0,25-5 \\
\mathrm{mm})\end{array}$ & $\begin{array}{c}\text { Pasir } \\
(0,063- \\
0,25 \mathrm{~mm})\end{array}$ & $\begin{array}{c}\text { Lumpur } \\
(<0,063 \\
\mathrm{mm})\end{array}$ & \\
\hline 1 & 5,3 & $-35,99$ & $-54,12$ & 3,56 & 24,81 & 71,62 & Lumpur berpasir \\
\hline 2 & 18,2 & $-37,49$ & $-61,72$ & 5,03 & 18,17 & 76,80 & Lumpur \\
\hline 3 & 12,5 & $-37,81$ & $-62,85$ & 2,83 & 15,32 & 81,85 & Lumpur \\
\hline 4 & 8,9 & $-37,73$ & $-62,16$ & 2,58 & 12,72 & 84,70 & Lumpur \\
\hline 5 & 5,5 & $-37,44$ & $-55,62$ & 4,60 & 20,17 & 75,23 & Lumpur \\
\hline 6 & 6,1 & $-28,12$ & $-49,69$ & 13,79 & 68,40 & 17,81 & Pasir halus \\
\hline 7 & 4,5 & $-28,40$ & $-49,17$ & 18,18 & 66,86 & 14,96 & Pasir halus \\
\hline 8 & 4,3 & $-27,36$ & $-47,44$ & 73,87 & 18,60 & 7,52 & Pasir sedang-kasar \\
\hline 9 & 4,6 & $-27,96$ & $-48,56$ & 72,58 & 22,53 & 4,88 & Pasir sedang-kasar \\
\hline 10 & 7,8 & $-28,02$ & $-50,96$ & 71,63 & 22,56 & 5,80 & Pasir sedang-kasar \\
\hline 11 & 2,7 & $-15,62$ & $-30,70$ & - & - & - & Karang \\
\hline
\end{tabular}




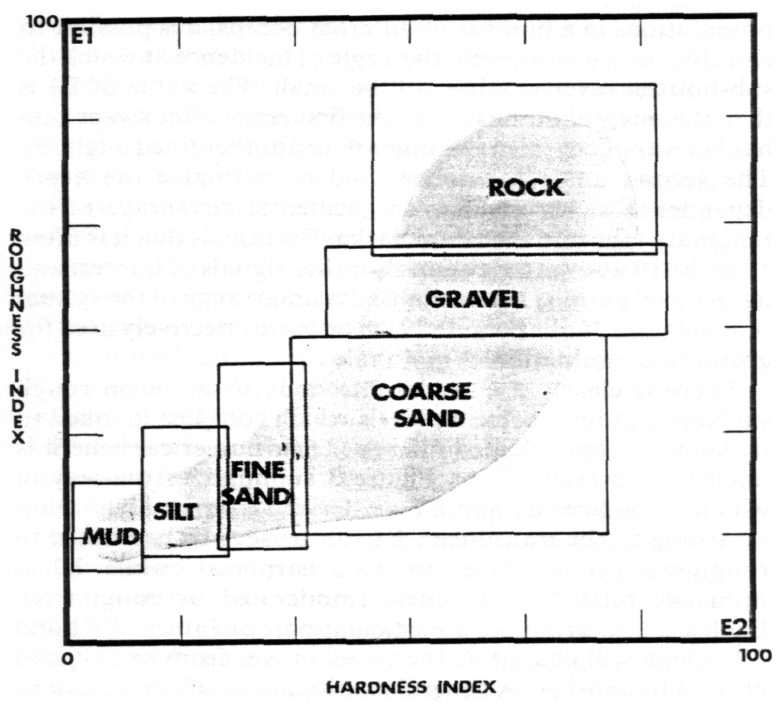

Gambar 2. Hubungan antara indeks kekasaran dan indeks kekerasan dasar perairan terhadap pantulan akustik (Chivers et al., 1990).

Perbedaan ukuran butiran substrat dasar perairan akan mempengaruhi intesitas nilai SV. Secara akustik, semakin besar ukuran butir substrat semakin tinggi nilai SV yang terdeteksi. Collier dan Brown (2005), terdapat korelasi positif antara kekuatan hambur balik dan ukuran butir sedimen, dimana hambur balik tertinggi berkorelasi dengan sedimen kasar. Gambar 3 menyajikan grafik hubungan antara persentase ukuran butiran substrat dasar yang perairan dengan nilai hambur balik akustik pertama dasar perairan yang keduanya merupakan hasil sampling jenis substrat dan perekaman akustik secara stasioner (stasiun 1 - 10). Dari Gambar 3 tersebut diperoleh hubungan antara persentase ukuran butiran substrat dasar perairan dengan kuat hambur balik akustiknya (E1) sangat erat, dimana regresi antara persentase butiran pasir kasar, pasir halus dan lumpur dengan kuat hambur balik akustik diperoleh koefisien korelasi masingmasing adalah 0,7802, 0,5289 dan 0,9939. Hal ini menunjukkan bahwa semakin tinggi persentase ukuran butiran yang lebih besar (pasir kasar) akan mempengaruhi nilai SV (E1) menjadi lebih tinggi, sebaliknya semakin tinggi persentase ukuran butiran yang lebih kecil atau butiran yang halus (lumpur) akan mempengaruhi nilai SV (E1) menjadi lebih rendah. Oleh karena itu, substrat pasir yang kasar akan memiliki tingkat kekasaran, kekerasan dan ukuran diameter fraksi lebih besar dari pada substrat pasir halus, pasir berlumpur atau lumpur. Sejalan dengan hasil penelitian Pujiyati et al. (2010), Ningsih et al. (2013) dan Manik (2015) bahwa ukuran butiran substrat sangat mempengaruhi nilai hambur balik dasar perairan, dimana semakin besar ukuran butiran akan semakin besar tingkat kekasaran dan kekerasan dari tipe substrat dasar perairan sehingga dapat menghasilkan energi pantulan akustik yang lebih besar dari tipe substrat dengan ukuran butiran yang lebih kecil. Sedangkan Goff et al. (2000) menyatakan bahwa nilai E1 akan berhubungan dengan nilai ukuran diameter fraksi dasar perairan yaitu sebesar 0,73.

Nilai SV substrat dasar perairan yang diperoleh dalam penelitian ini relatif tidak berbeda jauh dengan nilai SV yang diperoleh beberapa penelitian lain dengan menggunakan instrumen yang berbeda. Hasil penelitian Bemba (2011) mendapatkan nilai SV karang berkisar antara-17,32 dB sampai 12,17 dB, sedangkan Hamuna et al. (2014) SV karang berkisar antara $-21,54 \mathrm{~dB}$ sampai -18,24 dB menggunakan echosounder single beam frekuesnsi $200 \mathrm{kHz}$. Adapun beberapa hasil penelitian mngenai nilai SV pasir dan lumpur antara lain Manik et al. (2006) mendapatkan SV pasir -18.30 dB dan lumpur $-29,00 \mathrm{~dB}$, Pujiyati (2008) SV pasir -20.00 $\mathrm{dB}$ dan lumpur $-35,91 \mathrm{~dB}$, dan Ningsih et al. (2013) SV pasir -12,97 dB dan lumpur 30,87 dB. Sedangkan hasil penelitian Chakraborty et al. (2007), nilai SV pasir berkisar antara $-32,60 \mathrm{~dB}$ sampai $-29,40 \mathrm{~dB}$ dan lumpur berkisar antara $-40,51 \mathrm{~dB}$ sampai $-34,18 \mathrm{~dB}$.

Perbedaan nilai hambur balik akustik dasar perairan pada beberapa penelitian, selain disebabkan oleh kondisi perairan, dapat pula disebabkan karena penggunaan alat-alat dan frekuensi yang berbeda. 

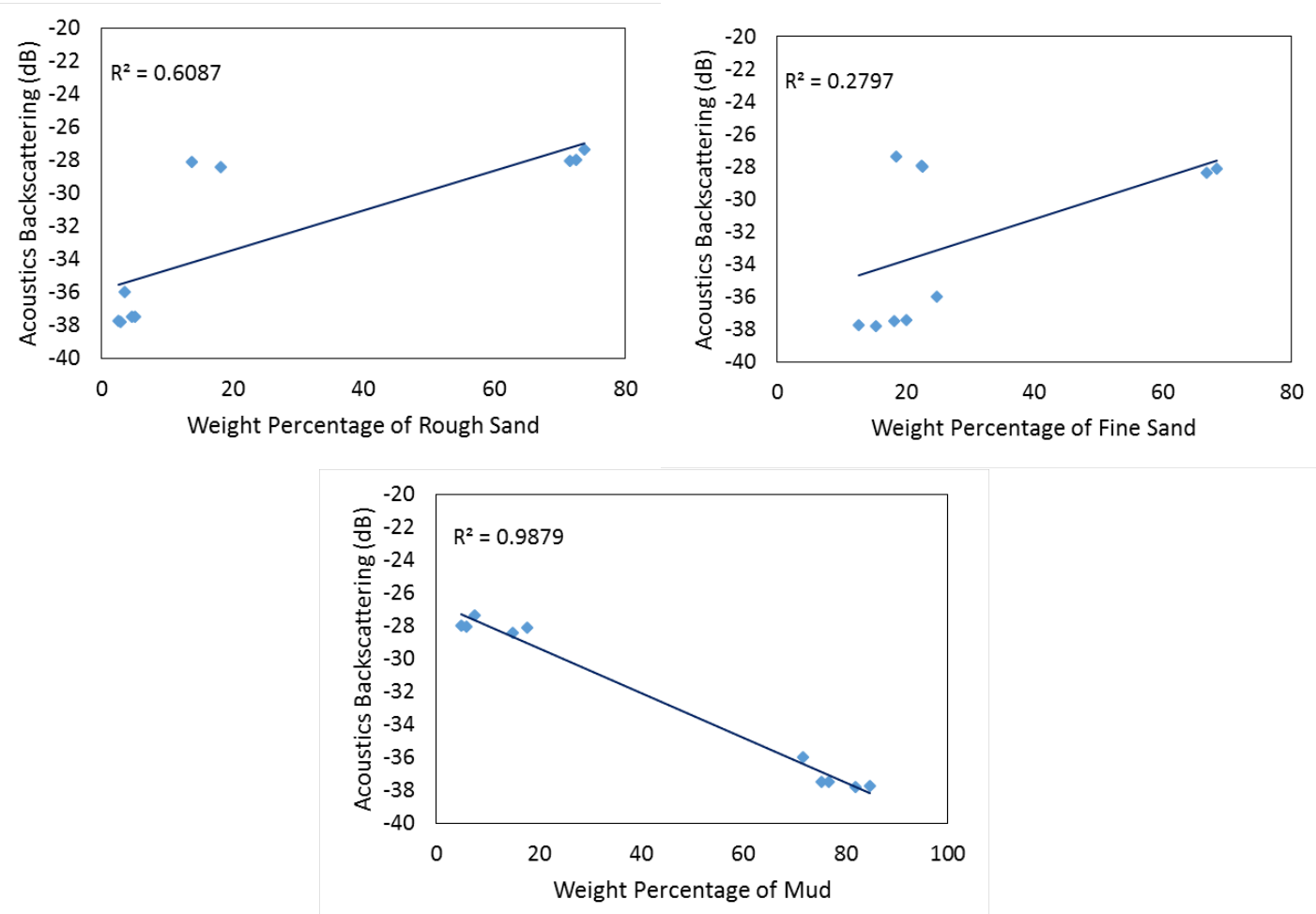

Gambar 3. Hubungan persentase ukuran butiran substrat (pasir kasar, pasir halus dan lumpur) terhadap kuat hambur balik akustik (E1) dasar perairan hasil perekaman stasioner.

Menurut Jackson dan Richardson (2007) bahwa pengaruh relief dasar perairan pada gelombang akustik yang datang sangat dipengaruhi oleh penggunaan frekuensi akustik. Penggunaan berbagai frekuensi yang berbeda pada instrumen akustik akan didapatkan hasil yang berbeda pula. Penggunaan frekuensi akan berhubungan langsung dengan absorpsi dalam medium (air laut). Absorpsi dapat memberikan pengaruh terhadap kuat lemahnya pantulan akustik dari target. Hasil penelitian Chakraborty et al. (2007) menunjukkan bahwa penggunaan dual frekuensi instrumen akustik akan memberikan hasil yang berbeda pada dasar perairan yang sama, frekuensi yang rendah akan memberikan nilai pantulan akustik yang lebih tinggi dibandingkan frekuensi yang tinggi.

\subsection{Klasifikasi dan Pemetaan Dasar Perairan}

Klasifikasi merupakan pengelompokkan objek berdasarkan informasi yang diperoleh dari data yang menjelaskan hubungan antar objek tersebut. Dari hasil klasifikasi dasar perairan, terdapat 3 kluster utama yaitu (1) kluster pasir yang terdiri dari 65 anggota kluster, (2) kluster lumpur yang terdiri dari 23 anggota kluster, dan (3) kluster karang terdiri dari 6 anggota kluster. Hasil analisis klasifikasi secara keseluruhan menunjukkan bahwa sebagian besar nilai pantulan akustik yang terekam tergolong dalam kategori substrat pasir (Gambar 4). Kondisi tersebut menunjukkan bahwa wilayah perairan jalur survei didominasi oleh tipe substrat pasir, sedangkan tipe karang yang ditemukan relatif sangat sedikit.

Adapun profil vertikal tipe substrat dasar perairan terhadap kedalaman sepanjang jalur survei berdasarkan hasil rekaman akustik disajikan pada Gambar 5. Berdasarkan kedalaman perairan, tipe substrat karang dominan berada pada kedalaman antara 2 - 3 meter, substrat pasir dominan pada kedalaman antara $2-10$ meter dan sebagian kecil pada kedalaman lebih dari 10 meter, sedangkan substrat lumpur dominan pada kedalaman lebih dari 10 meter. Kondisi 
tersebut sesuai dengan pernyataan Hutabarat dan Evans (1985) bahwa sebagian besar dasar laut yang lebih dalam ditutupi oleh partikel-partikel yang berukuran lebih kecil yang terdiri dari sedimen halus (lumpur), sedangkan perairan yang lebih dangkal (pantai) ditutupi oleh jenis partikel yang berukuran besar.

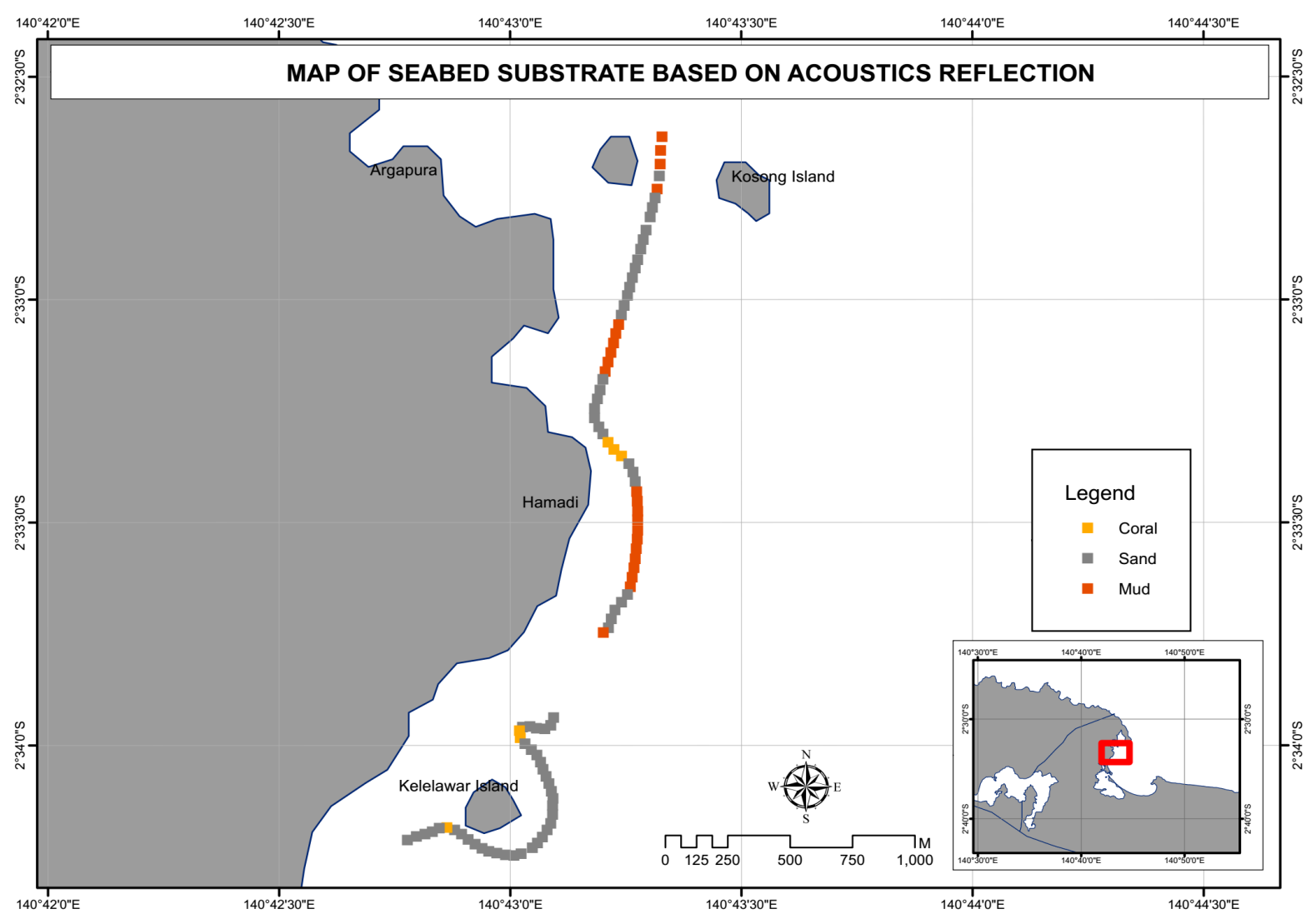

Gambar 4. Sebaran tipe substrat dasar perairan berdasarkan pantulan akustik.

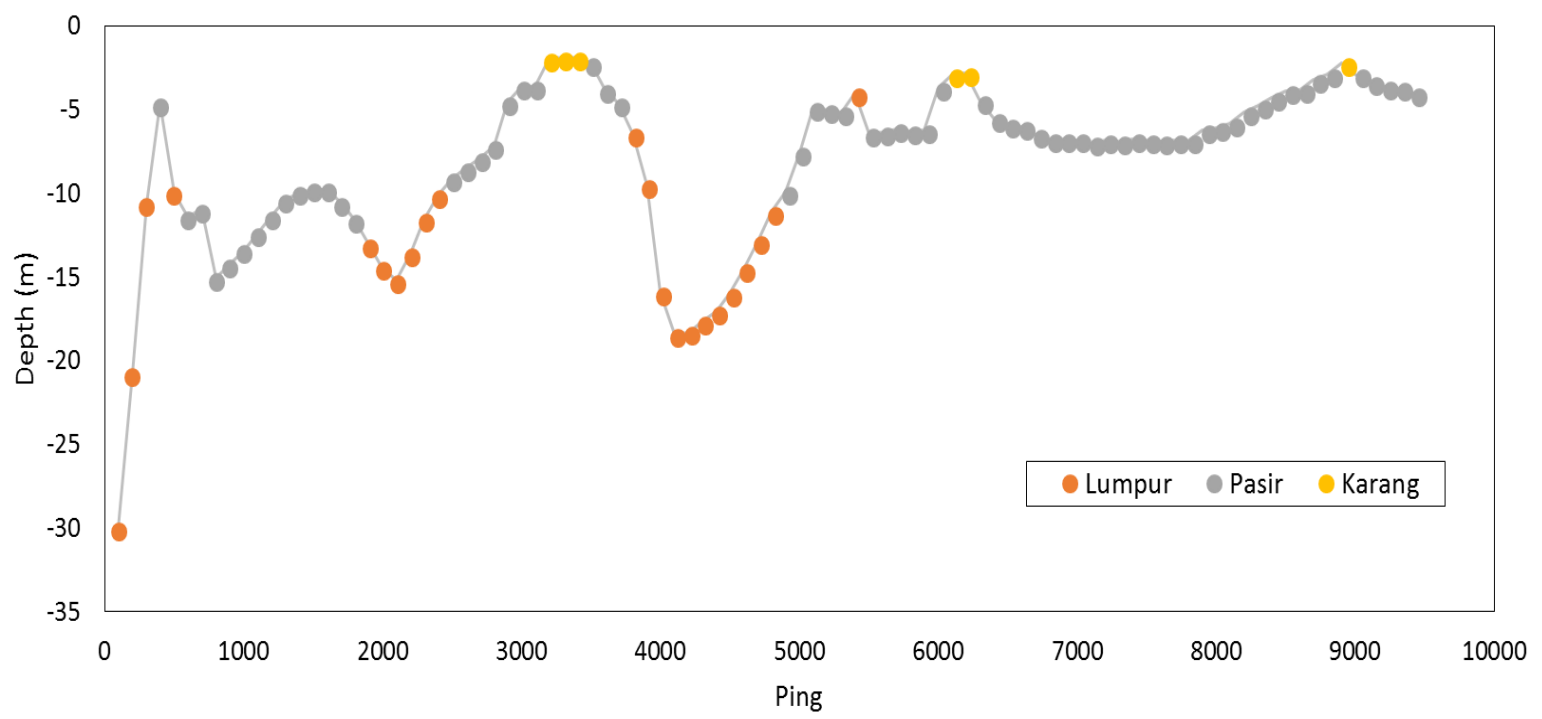

Gambar 5. Profil tipe substrat dasar terhadap kedalaman berdasarkan rekaman akustik. 


\section{KESIMPULAN}

Nilai hambur balik akustik yang terdiri dari nilai E1 dan E2 berbeda antara karang, pasir dan lumpur. Hambur balik akustik karang relatif lebih tinggi dibandingkan nilai pantulan akustik pasir dan lumpur. Selain tingkat kekasaran dan kekerasan dasar perairan, ukuran butiran substrat dasar perairan berpengaruh terhadap kuat hambur balik akustik. Berdasarkan hasil deteksi akustik, substrat karang berada pada kedalaman 2-3 m, substrat pasir pada kedalaman 2-10 m, dan substrat lumpur dominan pada kedalaman lebih dari $10 \mathrm{~m}$.

\section{UCAPAN TERIMA KASIH}

Ucapan terima kasih disampaikan kepada DRPM-RISTEKDIKTI yang telah membiayai penelitian ini melalui hibah Penelitian Kerjasama Antar Perguruan Tinggi (PEKERTI) tahun 2017 (Kontrak Penelitian Nomor: 01/UN20.2.2/PP/ PEKERTI/2017).

\section{DAFTAR PUSTAKA}

Bemba, J. 2011. Identifikasi dan klasifikasi lifeform karang menggunakan metode akustik. Tesis. Fakultas Perikanan dan Ilmu Kelautan. Institut Pertanian Bogor. $67 \mathrm{hlm}$.

Chakraborty, B., V. Mahale, G. Navelkar, B.R. Rao, R.G. Prabhudesai, B. Ingole, and G. Janakirinam. 2007. Acoustic characterization of seafloor habitats on the western continental shelf of India. ICES J. of Mar. Sci., 64:551-558.

Chivers, R.C., N. Emerson, and D. Burns. 1990. New acoustic processing for underwater surveying. Hydrology J., 56:9-17.

Collier, J.S. and C.J. Brown. 2005. Correlation of sidescan backscatter with grain size distribustion of surficial seabed sediments. Marine Geology, 214:431-449.

Demer, D.A., G.R. Cutter, J.S. Renfree, and J.L. Butler. 2009. A statisticalspectral method for echo classification. ICES J. of Mar. Sci., 66:1081-1090.

Freitas, R., A.M. Rodrigues, E. Morris, J.L. Perez-Llorens, and V. Quintino. 2008. Single-beam acoustic ground discrimination of shallow water habitats: $50 \mathrm{kHz}$ or $200 \mathrm{kHz}$ frequency survey? Estuarine, Coastal and Shelf Science, 78:613-622.

Gleason, A.C.R., R.P. Reid, and G.T. Kellison. 2008. Single-beam acoustics remote sensing for coral reef mapping. Proceedings of the $11^{\text {th }}$ international coral reef symposium; Ft. Lauderdale, Florida, 7-11 July 2008. 611-615 pp.

Goff, J.A, H.C. Olson and C.S. Duncan, 2000. Correlation of side scan backscatter intensity with grain size distribution of shelf sediments, New Jersey Margin. Geo-Marine latters, 20:43-49.

Hamilton, L.J. 2001. Acoustics seabed classification system. DSTO Technical Note DSTO-TN-0401, http://www.dsto.defence.gov.au/corpo rate/reports/DSTO-TN-0401.pdf.

[Retrieved on 12 March 2016].

Hamuna, B., S. Pujiyati, dan T. Hestirianoto. 2014. Karakterisasi pPantulan akustik karang menggunakan echosounder single bBeam. J. Integrasi, 6(2):129133.

Hutabarat, S. dan S.M. Evans. 1985. Pengantar oseanografi. Penerbit Universitas Indonesia (UI-Press). Jakarta. $159 \mathrm{hlm}$.

Jackson, D.R. and M.D. Richardson. 2007. High-frequency seafloor acoustics. Springer Science Business Media. New York. 616 p. 
Krumbien, W.C. and L.L. Sloss. 1951. Stratigraphy and sedimentation. W.H Freeman \& Co. San Fransisco. 497 p.

Legendre, L., and L. Legendre. 1998. Numerical ecology, $2^{\text {nd }}$ ed. Elsevier Publishing Co. Amsterdam. 852 p.

Manik, H.M., M. Furusawa, and K. Amakasu. 2006. Measurement of sea bottom surface backscattering strength by quantitative echosounder. Fish. Sci., 72(3):503-512.

Manik, H.M. 2015. Acoustic characterization of fish and seabed using underwater acoustic technology in Seribu Island Indonesia. J. Marine Sci. Res. Dev., 5: 157.

Ningsih, E.N., F. Supriyadi, dan S. Nurdawati. 2013. Pengukuran dan analisis nilai hambur balik akustik untuk klasifikasi dasar perairan Delta Mahakam. J. Lit. Perikan. Ind., 19(3):139-146.

Penrose, J.D., P.J.W. Siwabessy, A. Gavrilov, I. Parnum, L.J. Hamilton, A. Bickers, B. Brooke, D.A. Ryan, and P. Kennedy. 2005. Acoustics techniques for seabed classification. Technical Report 32. CRC for Coastal Zone Estuary \& Waterway Management. $130 \mathrm{p}$.

Pujiyati, S. 2008. Pendekatan metode hidroakustik untuk analisis keterkaitan antara tipe substrat dasar perairan dengan komunitas ikan demersal. Disertasi. Fakultas Perikanan dan Ilmu Kelautan. Institut Pertanian Bogor. $185 \mathrm{hlm}$.

Pujiyati, S., S. Hartati, dan W. Priyono. 2010. Efek ukuran butiran, kekasaran, dan kekerasan dasar perairan terhadap nilai hambur balik hasil deteksi hydroakustik. J. Ilmu dan Teknologi Kelautan Tropis, 2(1):59-67. http://dx.doi.org/10.29244/jitkt.v2i1.7 863.

Satyamarayana, Y., S. Naithani, and R. Anu. 2007. Seafloor sedimen classification from single beam echo sounder data using LVQ network. Mar. Geophys. Res., 28:95-99.

Simrad. 2012. Installation manual, Simrad EK15 multi-purpose scientific echosounder, http://www.simrad.com/ ek15. [Retrieved on 20 May 2017].

Siwabessy, P.J.W. 2001. An investigation of the relationship between seabed type and benthic and bentho-pelagic biota using acoustic techniques. The Curtin University of Technology. US. 284 p.

Siwabessy, P.J.W., L. Parnum, A. Gavrilov, and R. McCauley. 2006. Overview of coastal water habitat mapping research for the coastal CRC. Technical Report 86. CRC for Coastal Zone Estuary \& Waterway Management. 27 p.

Thermo, P.D., N.G. Pace, and Z.K.S. AlHamdani. 1988. Laboratory measurements of backscattering from marine sediments. J. Acoust. Soc. Am., 84:303-309.

Urick, R.J. 1983. Principles of underwater sound. $3^{\text {rd }}$ ed. Peninsula Publishing. California. $384 \mathrm{p}$.
Diterima
: 11 Agustus 2017
Direview
: 05 Januari 2018
: 23 Juli 2018 